\title{
Impact of Visceral Metastasis on Efficacy of Fulvestrant in Patients with Hormone Receptor-positive Recurrent Breast Cancer
}

\author{
YUMIKO KOI ${ }^{1}$, CHINAMI KOGA ${ }^{2}$, SAYURI AKIYOSHI ${ }^{3}$, TAKANOBU MASUDA ${ }^{2}$, HIDEKI IJICHI ${ }^{2}$, \\ YOSHIAKI NAKAMURA ${ }^{2}$, MAYUMI ISHIDA ${ }^{2}$, SHINJI OHNO ${ }^{3}$ and ERIKO TOKUNAGA ${ }^{2}$ \\ ${ }^{1}$ Surgical Oncology, Division of Radiation Biology and Medicine, \\ Graduate School of Biochemical \& Health Sciences, Hiroshima University, Hiroshima, Japan; \\ ${ }^{2}$ Department of Breast Oncology, National Hospital Organization Kyushu Cancer Center, Fukuoka, Japan; \\ ${ }^{3}$ Breast Center, The Cancer Institute Hospital of the Japanese Foundation of Cancer Research, Tokyo, Japan
}

\begin{abstract}
Background: Previous studies have suggested that the presence of visceral metastasis is a parameter useful in predicting the treatment efficacy of fulvestrant in patients with advanced breast cancer. Patients and Methods: We retrospectively examined the association between treatment efficacy and presence of visceral metastasis in 75 patients with hormone receptor-positive recurrent breast cancer who were treated with fulvestrant or no more than five lines of other endocrine monotherapy after recurrence. Results: Nineteen patients received fulvestrant, 10 of whom had visceral metastasis. The median time to progression was 4 months for the overall study population; it was significantly longer for patients with non-visceral metastasis (5.4 months; 95\% confidence interval=3.7-11.2 months) than for those with visceral metastasis $(3.3$ months; $95 \%$ confidence interval, 0.4-5.3 months; $p=0.01)$. No differences in time to progression were found between the groups of patients with visceral metastasis and non-visceral metastasis who underwent other endocrine therapies. Conclusion: Fulvestrant is more effective for patients with non-visceral metastasis of recurrent breast cancer with than for those with visceral metastasis.
\end{abstract}

Approximately $70-80 \%$ of breast cancers are hormone receptor (HR)-positive (1). The standard treatment for

Correspondence to: Eriko Tokunaga, Department of Breast Oncology, National Hospital Organization Kyushu Cancer Center, Notame 3-1-1, Minami-ku, Fukuoka 811-1395, Japan. Tel: +81 925413231,e-mail: tokunaga.e@nk-cc.go.jp

Key Words: Fulvestrant, visceral metastasis, endocrine therapy, breast cancer. recurrent HR-positive breast cancer is endocrine therapy unless the patient is in a life-threatening condition (2). In addition to hormone receptor expression and tumor burden, the predicted level of the sensitivity or refractoriness to endocrine therapy has been a high-priority concern in making treatment decisions (3). Since visceral metastasis is directly related to the life-threatening status, it is important to choose between endocrine therapy and chemotherapy to treat these patients. An additional layer of complexity has recently been brought into treatment for HR-positive recurrent breast cancer by new molecular targeted drugs, such as everolimus and inhibitors of cyclin-dependent kinase (CDK) 4/6 $(4,5)$.

Fulvestrant is a selective estrogen receptor (ER) downregulator that degrades the ER with no agonistic effects (6, 7). A phase 3 study comparing the efficacy of fulvestrant with anastrozole in patients with locally advanced or metastatic HR-positive breast cancer who had not previously received endocrine therapy (FALCON trial) showed the superior efficacy of fulvestrant (8). In this trial, a subgroup analysis of patients with versus without visceral metastasis was performed. Among patients treated with fulvestrant, median progression-free survival (PFS) was 22.3 months in those with non-visceral metastasis versus 13.8 months in those with visceral metastasis. In contrast, no differences in median PFS were found between these subgroups in the anastrozole-treated group. This subgroup analysis indicated that patients with non-visceral metastasis could benefit from fulvestrant more than those with visceral metastasis. Fulvestrant has been frequently used for recurrent breast cancer since its approval in Japan. In the present study, we evaluated the association between the efficacy of fulvestrant and the presence of visceral metastasis and compared it with that of other endocrine monotherapies in patients with recurrent breast cancer. 
Table I. Patient characteristics at the time of surgery for primary sites of breast cancer.

\begin{tabular}{|c|c|c|}
\hline Characteristic & $\mathrm{n}=75$ & $\%$ \\
\hline Median age (range), years & $56(37-86)$ & \\
\hline \multicolumn{3}{|l|}{ Menopausal status } \\
\hline Premenopausal & 26 & 34.7 \\
\hline Postmenopausal & 49 & 65.3 \\
\hline \multicolumn{3}{|l|}{$\mathrm{cT}$} \\
\hline 1 & 26 & 34.7 \\
\hline 2 & 33 & 44.0 \\
\hline$\geq 3$ & 16 & 21.3 \\
\hline \multicolumn{3}{|l|}{$\mathrm{cN}$} \\
\hline 0 & 24 & 32.0 \\
\hline 1 & 28 & 37.3 \\
\hline$\geq 2$ & 23 & 30.6 \\
\hline \multicolumn{3}{|l|}{ cStage } \\
\hline 1 & 11 & 14.6 \\
\hline 2 & 32 & 42.7 \\
\hline 3 & 32 & 42.7 \\
\hline \multicolumn{3}{|l|}{ Histological grade } \\
\hline 1 & 6 & 8.0 \\
\hline 2 & 45 & 60.0 \\
\hline 3 & 18 & 24.0 \\
\hline Unknown & 6 & 8.0 \\
\hline \multicolumn{3}{|l|}{ Estrogen receptor } \\
\hline Positive & 75 & 100.0 \\
\hline Negative & 0 & 0.0 \\
\hline \multicolumn{3}{|l|}{ Progesterone receptor } \\
\hline Positive & 53 & 70.7 \\
\hline Negative & 22 & 29.3 \\
\hline \multicolumn{3}{|l|}{ HER2 } \\
\hline Positive & 6 & 8.0 \\
\hline Negative & 59 & 78.7 \\
\hline Unknown & 10 & 13.3 \\
\hline
\end{tabular}

HER2: Human epidermal growth factor receptor 2.

\section{Patients and Methods}

Patients. Among 1855 patients with HR-positive breast cancer at clinical stage (cStage) I-III who underwent surgery between January 2000 and December 2014 at the Kyushu Cancer Center, 158 patients with recurrent breast cancer were identified. Among these patients, we were able to obtain the detailed records on the clinical course for 75 patients who received no more than five lines of endocrine monotherapy for recurrence. We retrospectively examined the relationship between the efficacy of endocrine treatment and the presence of visceral metastasis in these 75 patients.

Expression of ER, progesterone receptor $(P R)$, and human epidermal growth factor receptor 2 (HER2). Surgical specimens from primary surgery were subjected to immunohistochemistry (IHC) to assess the expression of ER, PR, and HER2. Tumors were considered to be ER- or PR-positive when $\geq 1 \%$ of the cells were stained. HER2 expression scores were determined according to the
Table II. Details of the adjuvant therapy for patients with breast cancer recurrence.

\begin{tabular}{|c|c|c|}
\hline & $\mathrm{n}=75$ & $\%$ \\
\hline \multicolumn{3}{|l|}{ Preoperative chemotherapy } \\
\hline Not performed & 58 & 77.3 \\
\hline Performed & 17 & 22.7 \\
\hline \multicolumn{3}{|l|}{ Adjuvant chemotherapy } \\
\hline Not performed & 43 & 57.3 \\
\hline Performed & 32 & 42.7 \\
\hline \multicolumn{3}{|l|}{ Chemotherapy regimen } \\
\hline Anthracycline + taxane & 24 & 32.0 \\
\hline Anthracycline & 17 & 22.7 \\
\hline Other & 4 & 5.3 \\
\hline \multicolumn{3}{|l|}{ Postoperative radiotherapy } \\
\hline Not performed & 41 & 54.7 \\
\hline Performed & 34 & 45.3 \\
\hline \multicolumn{3}{|l|}{ Radiation field } \\
\hline Breast only & 24 & 32.0 \\
\hline $\begin{array}{l}\text { Chest wall (or breast) }+ \\
\text { supraclavicular lymph node }\end{array}$ & 17 & 22.7 \\
\hline \multicolumn{3}{|l|}{ Adjuvant endocrine therapy } \\
\hline Not performed & 4 & 5.3 \\
\hline Performed & 71 & 94.7 \\
\hline \multicolumn{3}{|l|}{ Endocrine therapy } \\
\hline SERMs & 38 & 50.7 \\
\hline SERMs combined with LH-RH agonist & 5 & 6.7 \\
\hline AIs & 26 & 34.7 \\
\hline Switching SERM to AI & 2 & 2.7 \\
\hline $\begin{array}{l}\text { Median duration of adjuvant endocrine } \\
\text { therapy (range), years }\end{array}$ & $2.5(0.1-5.1)$ & \\
\hline
\end{tabular}

Anthracycline + taxane: sequential chemotherapy with anthracycline followed by a taxane, SERM: selective estrogen receptor modulator, LH-RH: luteinizing hormone-releasing hormone, AI: aromatase inhibitor.

guidelines of the American Society of Clinical Oncology/College of American Pathologists (9). Scores of 2+ were further assessed via fluorescence in situ hybridization (FISH). HER2 positivity was defined as either IHC $3+$ or IHC $2+$ and HER2 gene amplification by FISH (HER2/CEP ratio $>2.0$ ).

Endocrine therapy. We divided the drugs used for endocrine therapy into three groups according to their mechanism of action: selective ER modulators (SERMs), aromatase inhibitors (AIs), and fulvestrant. We included tamoxifen and toremifene in the SERM group. SERMs used in combination with a luteinizing hormonereleasing hormone (LH-RH) agonist or high-dose toremifene (120 $\mathrm{mg}$ ) for relapse treatment were excluded with the intention of evaluating the effects of individual agents used as monotherapy at their respective standard doses.

Statistical analysis. The JMP ${ }^{\circledR} 12$ software program (SAS Institute Inc., Cary, NC, USA) was used for statistical analysis. The KaplanMeier method was used to determine the time to progression (TTP), and the curves were compared by using the log-rank test. The significance threshold was set at $p<0.05$. 
Table III. Details of the first recurrence of breast cancer.

\begin{tabular}{lcc}
\hline & $\mathrm{n}=75$ & $\%$ \\
\hline Median time to first recurrence after surgery (range), years & $3.4(0.8-13.6)$ & 33.8 \\
Duration of prior adjuvant endocrine therapy (n=71) & & 46.5 \\
Recurrence within the first 2 years of adjuvant endocrine therapy & 24 & 19.7 \\
Recurrence in 2-5 years of adjuvant endocrine therapy & 14 & 57.3 \\
Recurrence after 5 years of adjuvant endocrine therapy & & 42.7 \\
First site of recurrence & 43 & 18.7 \\
Non-visceral metastasis & 32 & 24.0 \\
Visceral metastasis & & 6.7 \\
Visceral metastatic site (with overlap) & 14 & 18 \\
Liver & 5 & 38.7 \\
Lung & & 24.0 \\
Other & 29 & 5.3 \\
Non-visceral metastasis (with overlap) & 18 & 4 \\
Lymph nodes & & \\
Chest wall & & \\
\hline
\end{tabular}

\section{Results}

Clinicopathological features of patients with recurrence. The median age was 56 (range: $37-86)$ years, 49 patients $(65.3 \%)$ were postmenopausal, and 53 patients $(70.7 \%$ ) had lymph node metastasis when they underwent the surgery for primary sites. IHC of the primary tumor specimens revealed that all patients were positive for ER, 53 patients $(70.7 \%)$ were positive for PR, and 59 patients $(78.7 \%)$ were negative for HER2 (Table I). Seventeen patients $(22.7 \%)$ received neoadjuvant chemotherapy, 32 patients $(42.7 \%)$ received adjuvant chemotherapy, and 34 patients $(45.3 \%)$ received postoperative radiotherapy. Seventyone patients $(94.7 \%)$ received adjuvant endocrine therapy. Specifically, 38 of these patients $(50.7 \%)$ received a SERM, 26 patients $(34.7 \%)$ received an $\mathrm{AI}$, and two patients $(2.7 \%)$ received a SERM, which was subsequently switched to an AI. The median duration of adjuvant endocrine therapy was 2.5 years (range: 0.1-5.1 years) (Table II).

The median time from surgery to recurrence was 3.4 years (range: 0.9-13.6 years). Of 71 patients who received adjuvant endocrine therapy, $33(46.5 \%)$ received adjuvant endocrine therapy for 2-5 years before the first recurrence. The recurrence occurred in 61 patients $(85.9 \%)$ during their adjuvant endocrine therapy or within 12 months from the last day of treatment, while 10 patients $(14.1 \%)$ experienced recurrence more than 12 months after completing adjuvant endocrine therapy. In 32 patients $(42.7 \%)$, the first recurrence was attributed to visceral metastasis (Table III).

Endocrine treatments used for recurrence. SERMs, AIs, and fulvestrant were used for treatment of recurrent breast cancer in 45,87 , and 19 patients, respectively. In some patients, different drugs within the same mechanistic class were used: SERMs (tamoxifen and toremifene) in seven patients and AIs (anastrozole, letrozole, or exemestane) in 20 patients. No patient received two different drugs with the same mechanism of action in two consecutive lines of treatment (Table IV).

Visceral metastases were detected before endocrine therapy with SERMs, AIs, and fulvestrant was initiated in 22 (48.9\%), $42(48.3 \%)$, and 10 patients $(52.6 \%)$, respectively. Among them, metastases were found in the liver in 10 SERM-treated (22.2\%), 23 AI-treated (26.4\%), and seven fulvestrant-treated patients $(36.8 \%)$. In terms of the treatment line, SERMs and AIs were used more frequently for the firstto third-line regimens. On the other hand, fulvestrant was used at comparable frequencies for all treatment lines, thus accounting for a greater proportion than SERMs and AIs in patients undergoing late lines of treatment $(47.4 \%$, nine patients). The median TTP for patients receiving SERM, AI, and fulvestrant were 6.9(range: 0.4-65.0) months, 6.7 (range: 0.2-58.0) months, and 4.0 (range: 0.4-11.7) months, respectively.

Relationship between the presence of visceral metastasis and the efficacy of endocrine treatment. We then investigated the relationships between the presence of visceral metastasis and the efficacy of the endocrine therapy as evaluated in terms of TTP. Among patients treated with SERMs, the median TTP was 8.4 [95\% confidence interval (CI): 6.4-11.3] months in patients with non-visceral metastasis versus 4.3 (95\% CI: 2.1-13.8) months in those with visceral metastasis. The difference between the two groups was not of statistical significance $(p=0.52$, Figure 


\section{A}

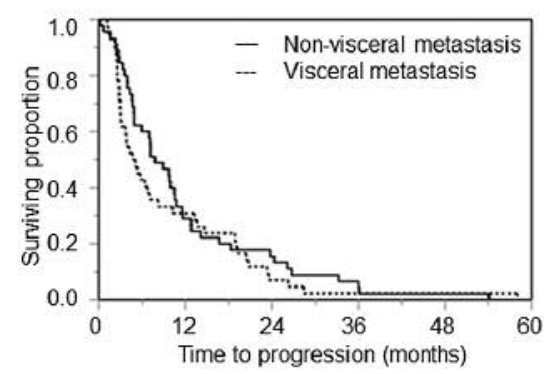

B

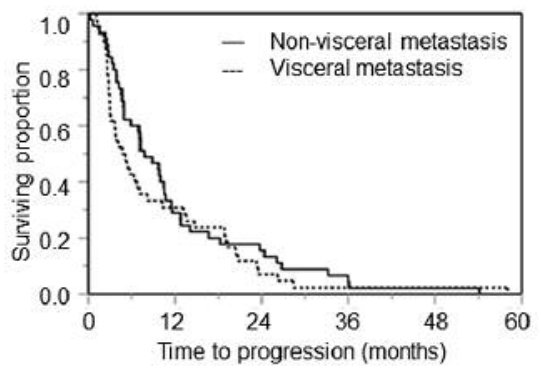

C

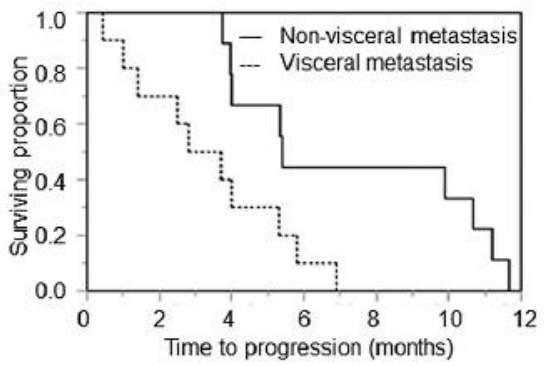

Figure 1. Time to progression according to the site of metastasis (non-visceral vs. visceral) for each type of endocrine treatment: selective estrogen receptor modulators $(A)$, aromatase inhibitors $(B)$, and fulvestrant $(C)$. Median time to progression (95\% confidence interval) for those with nonvisceral and those with visceral metastasis were 8.4 (6.4-11.3) vs. $4.3(2.1-13-8)$ months ( $p=0.53), 7.8$ (4.9-10.5) vs. 4.9 (3.0-7.1) months $(p=0.34)$, and $5.4(3.7-11.2)$ vs. $3.3(0.4-5.3)$ months $(p=0.01)$, respectively.

Table IV. Details of endocrine monotherapy for recurrent breast cancer.

\begin{tabular}{|c|c|c|c|}
\hline & SERMs $(\%)$ & AIs $(\%)$ & Fulvestrant $(\%)$ \\
\hline Number of patients & 45 & 87 & 19 \\
\hline Median TTP (range), months & $6.9(0.4-65.0)$ & $6.7(0.2-58.0)$ & $4.0(0.4-11.7)$ \\
\hline \multicolumn{4}{|l|}{ Treatment line } \\
\hline 1 & $2(4.5 \%)$ & $21(24.1 \%)$ & $1(5.2 \%)$ \\
\hline 2 & $12(26.7 \%)$ & $34(39.1 \%)$ & $5(26.3 \%)$ \\
\hline 3 & $19(42.2 \%)$ & $14(16.1 \%)$ & $4(21.1 \%)$ \\
\hline 4 & $6(13.3 \%)$ & $13(14.9 \%)$ & $5(26.3 \%)$ \\
\hline 5 & $6(13.3 \%)$ & $5(5.7 \%)$ & $4(21.1 \%)$ \\
\hline \multicolumn{4}{|c|}{ Metastatic site before administration } \\
\hline Non-visceral & $23(51.1 \%)$ & $45(51.7 \%)$ & $9(47.4 \%)$ \\
\hline Visceral & $22(48.9 \%)$ & $42(48.3 \%)$ & $10(52.6 \%)$ \\
\hline \multicolumn{4}{|l|}{ Visceral metastatic site* } \\
\hline Liver & $10(22.2 \%)$ & $23(26.4 \%)$ & $7(36.8 \%)$ \\
\hline Lung & $15(35.1 \%)$ & $24(27.6 \%)$ & $6(31.6 \%)$ \\
\hline Other & $4(5.4 \%)$ & $5(5.7 \%)$ & 0 \\
\hline
\end{tabular}

SERM: Selective estrogen receptor modulator, AI: aromatase inhibitor, TTP: time to progression. *With overlapping data.

1A). Similarly, among AI-treated patients, the median TTP was 7.8 (95\% CI: 4.9-10.5) months in patients with nonvisceral metastasis versus 4.9 (95\% CI: 3.0-7.1) months in those with visceral metastasis; the difference was not of significance ( $p=0.34$, Figure 1B). In contrast, TTP was significantly longer in the non-visceral metastasis subgroup [5.4 (95\% CI: 3.7-11.2) months] than in the visceral metastasis subgroup [3.3 months, 95\% CI: 0.4-5.3, $p=0.01$ ] of fulvestrant-treated patients, although the lengths of TTP in the non-visceral metastasis and visceral metastasis subgroups of fulvestrant-treated patients were shorter compared to the respective subgroups of SERM-treated and AI-treated patients (Figure 1C).

\section{Discussion}

In the present study, we retrospectively evaluated TTP in terms of the absence or presence of visceral metastasis in patients with HR-positive recurrent breast cancer who received no more than five lines of endocrine monotherapy with SERMs, AIs, or fulvestrant. The median TTP for fulvestrant-treated patients with non-visceral metastasis was significantly longer than that that for fulvestrant-treated patients with visceral metastasis, whereas no significant differences depending on the presence or absence of visceral metastasis were observed among the patients treated with SERMs or AIs. These results are consistent with the findings 
from the FALCON trial showing that the treatment efficacy of fulvestrant was different according to the presence of visceral metastases (8).

The CONFIRM trial compared the efficacy of fulvestrant at different doses $(250 \mathrm{mg} v \mathrm{~s} .500 \mathrm{mg}$ ) in patients with recurrent or metastatic breast cancer who had recurrence on or after adjuvant endocrine therapy or progression following endocrine therapy for advanced disease (10). This trial excluded patients who received more than two regimens of endocrine therapy before fulvestrant was used for recurrent or metastatic cancer. The median PFS was 6.5 months in patients treated with 500 $\mathrm{mg}$ of fulvestrant. Sixty-four percent of patients in the group treated with $500 \mathrm{mg}$ fulvestrant received adjuvant endocrine therapy and the median time from diagnosis to recurrence was 60.5 months. On the other hand, we evaluated patients who received fulvestrant in any of the five treatment lines, and the median TTP was 4.0 months. In our study, $95 \%$ of patients received adjuvant endocrine therapy, and the median time to recurrence was 3.3 years. It is possible that we included patients less responsive to endocrine therapy than those in the CONFIRM trial. Furthermore, our patients tended to have received fulvestrant at later stages of endocrine therapy (mostly as the third- or later line), and the shorter TTP observed in our study may be attributable to this difference. In addition, the proportion of patients who had liver metastasis, which is associated with poor prognosis, was higher in the fulvestrant group than other treatment-based groups (11). This is another possible contributor to the shorter TTP of the fulvestranttreated patients in our study.

Management of visceral metastasis is crucial since it is related to poorer prognosis. Some subgroup analyses evaluating the relationship between the effect of fulvestrant and the presence of visceral metastasis have been performed $(12,13)$. They have reported that fulvestrant was effective regardless of the presence or absence of visceral metastasis in terms of the clinical benefit rate or the duration of response $(12,13)$. Meanwhile, in a prospective trial evaluating the efficacy of fulvestrant, a multivariate analysis has shown that visceral involvement was a prognostic factor for PFS (14). In our study, TTP was significantly longer for fulvestrant-treated patients with non-visceral metastasis than in those with visceral metastasis. These results suggest that the use of fulvestrant in patients with non-visceral metastasis is worth considering even at a relatively late line.

Our study has limitations. This study was performed retrospectively, and the number of the patients included in this study was small. In addition, we did not consider discordance of the HR status between primary tumors and metastatic sites, which might relate to the treatment efficacy (15). Surgical specimens are more commonly used to screen for tumor biomarkers in routine clinical practice because the reassessment of biomarkers is not always possible depending on the site of metastasis (16).
In addition, it is possible that we included patients whose tumor had endocrine resistance before treatment. Estrogen receptor 1 (ESRl) gene mutations have recently been identified as causes of acquired resistance to endocrine therapy (17-22). Jeselsohn et al. have described ESRl mutations as found in $12 \%(9 / 76 ; 95 \% \mathrm{CI}, 6 \%-21 \%)$ of metastatic tumors, while they were found very rarely in primary tumors (20). However, the ESRI gene status could not be evaluated in this study. It is possible that an earlier line of treatment may have affected the efficacy of later lines; however, the number of patients in our study was insufficient to assess the treatment efficacy by treatment line.

The use of molecular targeted drugs in combination with endocrine therapy medicines has been rigorously studied recently, and treatment choices for HR-positive recurrent breast cancer have increased remarkably. However, the effects of the new agents on overall survival are still unclear, and endocrine monotherapy remains to be the treatment of choice for some patients because of the expensiveness and unique side effects of molecular targeted drugs. The results of our study suggest that fulvestrant is favorable for patients with non-visceral metastasis in the daily clinical practice.

\section{Acknowledgements}

The Authors thank Ms. Kimiko Baba and Ms. Yumiko Tatesaka at the National Hospital Organization Kyushu Cancer Center for managing data as doctor's assistants.

\section{References}

1 Iwase H: Current topics and perspectives on the use of aromatase inhibitors in the treatment of breast cancer. Breast Cancer 15: 278-290, 2008.

2 Hortobagyi GN: Treatment of breast cancer. N Engl J Med 339: 974-984, 1998.

3 Cardoso F, Costa A, Norton L, Senkus E, Aapro M, André F, Barrios CH, Bergh J, Biganzoli L, Blackwell KL, Cardoso MJ, Cufer T, El Saghir N, Fallowfield L, Fenech D, Francis P, Gelmon K, Giordano SH, Gligorov J, Goldhirsch A, Harbeck N, Houssami N, Hudis C, Kaufman B, Krop I, Kyriakides S, Lin UN, Mayer M, Merjaver SD, Nordström EB, Pagani O, Partridge A, Penault-Llorca F, Piccart MJ, Rugo H, Sledge G, Thomssen C, Van't Veer L, Vorobiof D, Vrieling C, West N, Xu $B$ and Winer E: ESO-ESMO 2nd international consensus guidelines for advanced breast cancer (ABC2). Ann Oncol 10: 1871-1888, 2014.

4 Baselga J, Campone M, Piccart M, Burris III HA, Rugo HS, Sahmoud T, Noguchi S, Gnant M, Pritchard KI, Lebrun F, Beck JT, Ito Y, Yardley D, Deleu I, Perez A, Bachelot T, Vittori L, Xu Z, Mukhopadhyay P, Lebwohl D and Hortobagyi GN: Everolimus in postmenopausal hormone-receptor-positive advanced breast cancer. N Engl J Med 366: 520-529, 2012.

5 Cristofanilli M, Turner NC, Bondarenko I, Ro J, Im SA, Masuda N, Colleoni M, DeMichele A, Loi S, Verma S, Iwata H, Harbeck $\mathrm{N}$, Zhang K, Theall KP, Jiang Y, Bartlett CH, Koehler M and Slamon D: Fulvestrant plus palbociclib versus fulvestrant plus 
placebo for treatment of hormone-receptor-positive, HER2negative metastatic breast cancer that progressed on previous endocrine therapy (PALOMA-3): final analysis of the multicentre, double-blind, phase 3 randomised controlled trial. Lancet Oncol 17: 425-439, 2016.

6 Howell A, Osborne CK, Morris C and Wakeling AE: ICI 182,780 (Faslodex): development of a novel, "pure" antiestrogen. Cancer 89: 817-825, 2000.

7 McDonnell DP and Wardell SE: The molecular mechanisms underlying the pharmacological actions of ER modulators: implications for new drug discovery in breast cancer. Curr Opin Pharmacol 10: 620-628, 2010.

8 Robertson JF, Bondarenko IM, Trishkina E, Dvorkin M, Panasci L, Manikhas A, Shparyk Y, Cardona-Huerta S, Cheung KL, Philco-Salas MJ, Ruiz-Borrego M, Shao Z, Noguchi S, Rowbottom J, Stuart M, Grinsted LM, Fazal M and Ellis MJ: Fulvestrant $500 \mathrm{mg}$ versus anastrozole $1 \mathrm{mg}$ for hormone receptor-positive advanced breast cancer (FALCON): an international, randomised, double-blind, phase 3 trial. Lancet Oncol 388: 2997-3005, 2016.

9 Wolff AC, Hammond ME, Hicks DG, Dowsett M, McShane LM, Allison KH, Allred DC, Bartlett JM, Bilous M, Fitzgibbons P, Hanna W, Jenkins RB, Mangu PB, Paik S, Perez EA, Press MF, Spears PA, Vance GH, Viale G, Hayes DF; American Society of Clinical Oncology; College of American Pathologists. Recommendations for human epidermal growth factor receptor 2 testing in breast cancer: American Society of Clinical Oncology/College of American Pathologists clinical practice guideline update. J Clin Oncol 31: 3997-4013, 2013.

10 Di Leo A, Jerusalem G, Petruzelka L, Torres R, Bondarenko IN, Khasanov R, Verhoeven D, Pedrini JL, Smirnova Iya, Lichinitser MR, Pendergrass, Garnett S, Lindemann JPO, Sapunar F and Martin M: Results of the CONFIRM Phase III Trial Comparing Fulvestrant $250 \mathrm{mg}$ With fulvestrant $500 \mathrm{mg}$ in postmenopausal women with estrogen receptor-positive advanced breast cancer. J Clin Oncol 28: 4594-600, 2010.

11 Ito Y, Tokudome N and Takahashi S: Strategy of treatment for liver metastasis of breast cancer. Jpn J Breast Cancer 20: 6-11, 2005.

12 Mauriac L, Pippen JE, Quaresma Albano J, Gertler SZ and Osborne CK: Fulvestrant (Faslodex) versus anastrozole for the second-line treatment of advanced breast cancer in subgroups of postmenopausal women with visceral and non-visceral metastases: combined results from two multicentre trials. Eur J Cancer 39: 1228-1233, 2003.

13 Mauriac L, Romieu G and Bines J: Activity of fulvestrant versus exemestane in advanced breast cancer patients with or without visceral metastases: data from the EFECT trial. Breast Cancer Res Treat 117: 69-75, 2009.

14 Moscetti L, Fabbri MA, Natoli C, Vici P, Gamucci T, Sperduti I, Iezzi L, Iattoni E, Pizzuti L, Roma C, Vaccaro A, D'Auria G, Mauri M, Mentuccia L, Grassadonia A, Barba M and Ruggeri EM: Fulvestrant 500 milligrams as endocrine therapy for endocrine sensitive advanced breast cancer patients in the real world: the Ful500 prospective observational trial. Oncotarget, 2017. doi: 10.18632/oncotarget.17262. [Epub ahead of print]
15 Liedtke C, Broglio K, Moulder S, Hsu L, Kau SW, Symmans WF, Albarracin C, Meric-Bernstam F, Woodward W, Theriault RL, Kiesel L, Hortobagyi GN, Pusztai L and Gonzalez-Angulo AM: Prognostic impact of discordance between triple-receptor measurements in primary and recurrent breast cancer. Ann Oncol 20: 1953-1958, 2009.

16 Amir E and Clemons M: Should a biopsy be recommended to confirm metastatic disease in women with breast cancer? Lancet Oncol 10: 933-935, 2009.

17 Oesterreich S and Davidson NE: The search for ESR1 mutations in breast cancer. Nature Genetics 45: 415-416, 2013.

18 Toy W, Shen Y, Won H, Green B, Sakr RA, Will M, Li Z, Gala K, Fanning S, King TA, Hudis C, Chen D, Taran T, Hortobagyi G, Greene G, Berger M, Baselga J and Chandarlapaty S: ESR1 ligand-binding domain mutations in hormone-resistant breast cancer. Nature Genetics 45: 1439-1445, 2013.

19 Robinson DR, Wu YM, Vats P, Su F, Lonigro RJ, Cao X, Kalyana-Sundaram S, Wang R, Ning Y, Hodges L, Gursky A, Siddiqui J, Tomlins SA, Roychowdhury S, Pienta KJ, Kim SY, Roberts JS, Rae JM, Van Poznak CH, Hayes DF, Chugh R, Kunju LP, Talpaz M, Schott AF and Chinnaiyan AM: Activating ESR1 mutations in hormone-resistant metastatic breast cancer. Nature Genetics 45: 1446-1451, 2013.

20 Jeselsohn R, Yelensky R, Buchwalter G, Frampton G, MericBernstam F, Gonzalez-Angulo AM, Ferrer-Lozano J, PerezFidalgo JA, Cristofanilli M, Gómez H, Arteaga CL, Giltnane J, Balko JM, Cronin MT, Jarosz M, Sun J, Hawryluk M, Lipson D, Otto G, Ross JS, Dvir A, Soussan-Gutman L, Wolf I, Rubinek T, Gilmore L, Schnitt S, Come SE, Pusztai L, Stephens P, Brown $\mathrm{M}$ and Miller VA: Emergence of constitutively active estrogen receptor- $\alpha$ mutations in pretreated advanced estrogen receptorpositive breast cancer. Clin Cancer Res 20: 1757-1767, 2014.

21 Baselga J, Campone M, Piccart M, Burris HA 3rd, Rugo HS, Sahmoud T, Noguchi S, Gnant M, Pritchard KI, Lebrun F, Beck JT, Ito Y, Yardley D, Deleu I, Perez A, Bachelot T, Vittori L, Xu Z, Mukhopadhyay P, Lebwohl D and Hortobagyi GN: Everolimus in postmenopausal hormone-receptor-positive advanced breast cancer. N Engl J Med 366: 520-529, 2012.

22 Chandarlapaty S, Chen D, He W, Sung P, Samoila A, You D, Bhatt T, Patel P, Voi M, Gnant M, Hortobagyi G, Baselga J and Moynahan ME: Prevalence of ESR1 mutations in cell-free DNA and outcomes in metastatic breast cancer: A secondary analysis of the BOLERO-2 clinical trial. JAMA Oncol 2: 1310-1315, 2016. 